\title{
Decentralized Care for Rifampin-Resistant Tuberculosis, Western Cape, South Africa
}

\author{
Sarah V. Leavitt, Karen R. Jacobson, Elizabeth J. Ragan, Jacob Bor, \\ Jennifer Hughes, Tara C. Bouton, Tania Dolby, Robin M. Warren, Helen E. Jenkins
}

In 2011, South Africa implemented a policy to decentralize treatment for rifampin-resistant tuberculosis (TB) to reduce durations of hospitalization and enable local treatment. We assessed policy implementation in Western Cape Province, where services expanded from 6 specialized TB hospitals to 406 facilities, by analyzing National Health Laboratory Service data on TB during 2012-2015. We calculated the percentage of patients who visited a TB hospital $\leq 1$ year after rifampin-resistant TB diagnosis, the median duration of their hospitalizations, and the total distance between facilities visited. We assessed temporal changes with linear regression and stratified results by location. Of 2,878 patients, $65 \%$ were from Cape Town. In Cape Town, 29\% visited a TB hospital; elsewhere, $68 \%$ visited a TB hospital. We found that hospitalizations and travel distances were shorter in Cape Town than in the surrounding areas.

Gouth Africa has a high tuberculosis (TB) prevaOlence, complicated by multidrug resistance to rifampin and isoniazid (1). In 2018, multidrug-resistant (MDR) and rifampin-resistant (RR) TB accounted for $3.4 \%$ of new and $7.1 \%$ of previously treated cases in South Africa (1). These forms of TB require more

Author affiliations: Boston University, Boston, Massachusetts, USA (S.V. Leavitt, K.R. Jacobson, E.J. Ragan, J. Bor, T.C. Bouton, H.E. Jenkins); Boston Medical Center, Boston (K.R. Jacobson, E.J. Ragan, T.C. Bouton); University of the Witwatersrand, Johannesburg, South Africa (J. Bor); Stellenbosch University, Stellenbosch, South Africa (J. Hughes, R.M. Warren); Brown University, Providence, Rhode Island, USA (T.C. Bouton); Green Point Tuberculosis Laboratory, Cape Town, South Africa (T. Dolby); South African Medical Research Council Centre for Tuberculosis Research, Cape Town (R.M. Warren); Department of Science and Technology-National Research Foundation Centre of Excellence for Biomedical Tuberculosis Research, Cape Town (R.M. Warren)

DOI: https://doi.org/10.3201/eid2703.203204 complex and lengthy treatments than drug-susceptible TB. Before 2011, most patients with MDR/RR TB in South Africa were hospitalized in dedicated TB hospitals, which were considered better than other facilities for managing infection control, regimen complexities, and side effects. However, centralized care might have contributed to delayed initiation of second-line drugs for MDR/RR TB, high pretreatment death rates caused by limited bed capacity, and patient loss to follow-up because of long-term hospitalization of clinically stable patients $(2,3)$.

A 2009 pilot program in Khayelitsha township, Cape Town (4), South Africa, demonstrated that community-based care improved case detection. It also reduced death, health system costs, and treatment delays (3,5-11). In 2011, the South African National Department of Health implemented a national policy to decentralize and deinstitutionalize MDR/ RR TB care (2). In Western Cape, MDR/RR TB care decentralization enabled clinically stable patients to initiate second-line TB treatment at 1 of 406 local facilities offering TB care instead of the province's 6 specialized TB hospitals (12). The policy also reduced the required duration of TB hospitalizations for patients who required hospitalization (2). Because of the reduced density of TB hospitals outside Cape Town, the potential policy effects are largest in rural areas. However, long distances between facilities and lack of resources and experienced providers pose challenges to implementation in rural areas.

Despite these demonstrated benefits of decentralization, data analyzing its effects on hospitalization rates, duration, and travel distance in Western Cape are scarce. The National Health Laboratory Service (NHLS) conducts and records most laboratory tests in South Africa. We used NHLS data to track where patients received care for RR TB in the year after their diagnoses. We identified temporal trends in patient 
contact with TB hospitals, estimated hospital stay duration and distance traveled between facilities during early implementation of the national decentralization policy in Western Cape. We compared these metrics between Cape Town and more rural Western Cape districts.

\section{Methods}

\section{Data Source}

We extracted records of TB laboratory tests conducted on clinical samples at the NHLS TB laboratory in Green Point, Cape Town, during January 1, 2012-July 31,2015 . These tests were used to diagnose and monitor TB cases in the Western Cape. Samples originated from patients at various facilities, including specialized TB hospitals, primary healthcare clinics, mobile clinics, regional hospitals, and district hospitals. The NHLS records data on patients receiving tests through the public healthcare system, which conducts $93 \%$ of all TB tests nationally (13). The study was approved by Stellenbosch University's Health Research Ethics Committee (protocol no. N09/11/296) and Boston University's Institutional Review Board (no. H-38441). Given the study's retrospective nature, an informed consent waiver was granted.

During the study period, the Western Cape's TB investigation policy required that facilities submit 2 clinical samples from each patient to the nearest NHLS laboratory (14). Usually, the first sample was tested with Xpert MTB/RIF (Cepheid, https:/ / www.cepheid.com). If RR TB was detected, the second sample was sent to the Green Point laboratory for smear microscopy, culturing with the mycobacterial growth indicator tube (Becton, Dickinson, and Company, https:/ / www.bd.com), and drug susceptibility testing (DST). Line probe assays (LPAs) conducted by using GenoType MTBDRplus (Hain Lifescience $\mathrm{GmbH}$, https://www.hain-lifescience.de) confirmed the presence of Mycobacterium tuberculosis and genes for resistance to rifampin and other first-line drugs. Phenotypic DST was used to detect genes conferring second-line drug (SLD) resistance. Although samples from tertiary (non-TB) hospitals with their own culture laboratories are not included in this dataset, the laboratory in Green Point conducts most culture-based and LPA confirmatory testing for TB in the Western Cape; therefore, this dataset includes most patients with RR TB in this province (Appendix, https://wwwnc.cdc.gov/EID/article/27/3/203204-App1.pdf).

Each NHLS record represents a single laboratory test but lacks a unique patient identifier. Therefore, to track patients over time, we used a patient matching algorithm to link samples belonging to the same patient. This algorithm, previously applied to NHLS HIV data, estimates the probability that records belong to the same patient on the basis of name, birthdate, sex, and facility data (15; J. Bor, unpub. data, https://www.biorxiv.org/content/ early/2018/11/02/450304) (Appendix).

\section{Definitions}

We defined a patient with RR TB as someone who submitted $\geq 1$ clinical sample with bacteriological confirmation of $M$. tuberculosis and rifampin resistance according to Xpert MTB/RIF, LPA, phenotypic DST, or a combination of these testing methods at the NHLS laboratory in Green Point. We defined the taken date as the date the sample was obtained from a patient. We considered the taken date of the first RR TB-positive sample to be the patient's initial sample date and the diagnosis date (Appendix). We defined a visit as a unique day in which a patient submitted $\geq 1$ laboratory sample. Time in care was defined as 1 year from the initial RR TB sample or until the most recent sample in the study timeframe, whichever was earlier.

\section{Study Population}

We analyzed each patient's TB laboratory samples in the year after that patient's initial RR TB sample was submitted to the NHLS during January 1, 2012-July 31, 2015. Using specific exclusion criteria (Figure 1), we excluded samples that were from locations outside Western Cape, collected for research purposes, submitted with invalid identifying data (e.g., names containing the words "control," "staff," "Ecoli", etc.), or had facility codes that could not be linked to a physical location.

After linking samples to individual patients, we excluded patients whose initial RR TB sample was submitted after July 1, 2014, enabling us to study 12 months of follow-up for each patient. Some patients might have had less time in care if they died, moved out of the province, or were otherwise lost to followup, after which point these patients would no longer be included in the Western Cape public healthcare system. Because we could not correlate laboratory results with clinical records, we excluded patients whose initial RR TB sample was submitted during the first 3 months of the study (January 1-March 31, 2012) because this sample might not have been their diagnostic sample. We excluded patients who had no subsequent laboratory samples submitted to the NHLS because we assumed that those patients were less 
likely to have initiated treatment or stayed in care. Finally, we excluded patients who were less likely to have been affected by the decentralization policy: those in correctional facilities, those with documented SLD resistance, and children $<15$ years of age at diagnosis.

\section{Mapping Patient Movement}

In the NHLS database, each sample is registered with a collecting facility code. We determined the facility name, type, and geocoordinates from NHLS and
National Department of Health reference lists. We grouped facilities into 3 categories: specialized TB hospitals, non-TB hospitals (i.e., all other hospitals), and clinics (i.e., all other location types). We validated geocoordinates on Google Maps (https://maps. google.com); researchers and healthcare providers in South Africa resolved discrepancies. We combined facilities of the same type and geographic location into a single entity. We used the code associated with the samples from each patient to track patient movement between facilities.

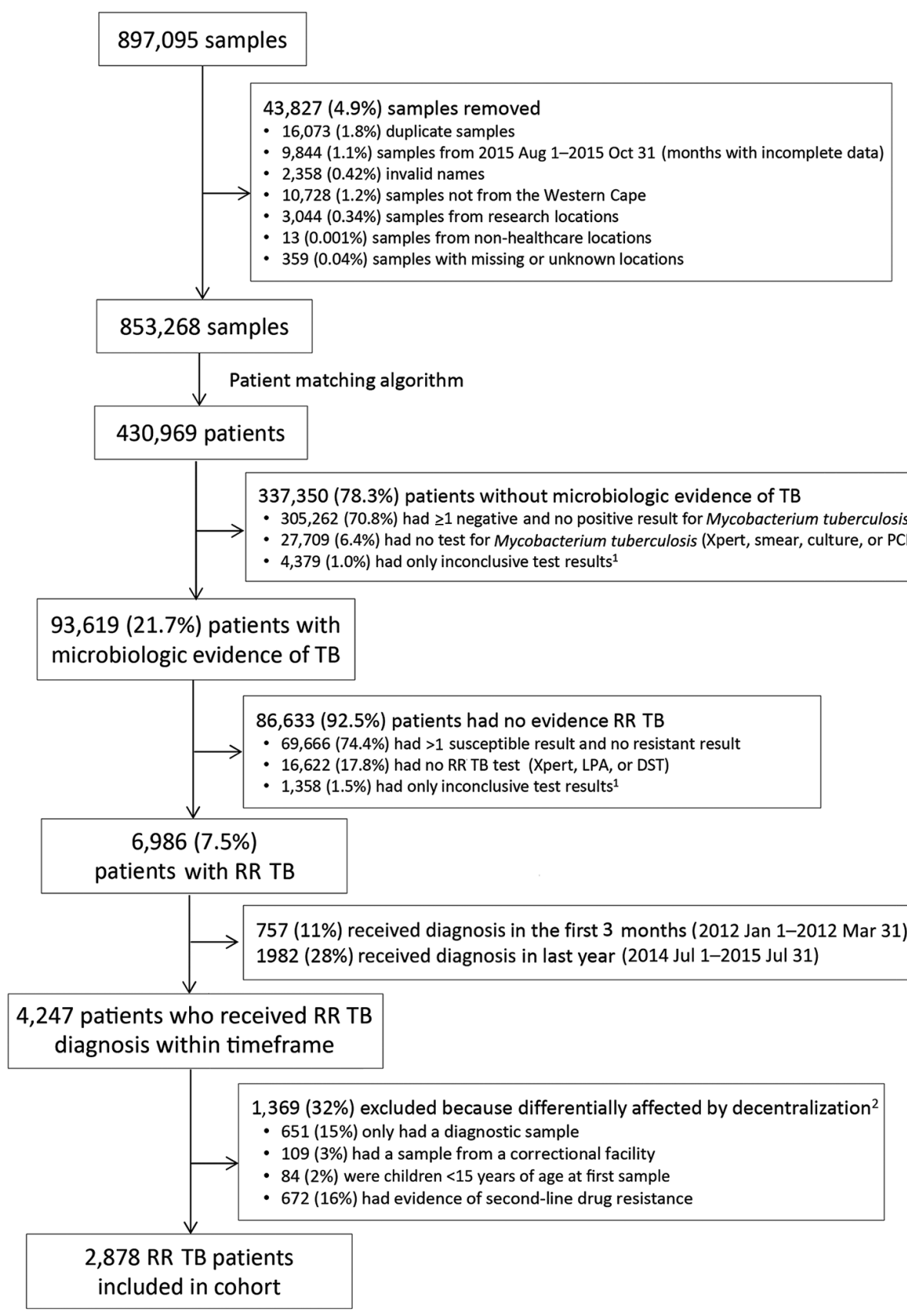

Figure 1. Flow diagram showing identification of adult patients with RR TB, Western Cape, South Africa, 2012-2014. Patients did not have second-line drug resistance and attended $\geq 2$ clinic visits. The following test results were classed as inconclusive: inconclusive, error, unsuccessful, specimen container received empty, no result, lost viability, contaminated, specimen accidentally destroyed, insufficient specimen, or leaky specimen. The total number of patients excluded does not equal the sum of the individual categories because some patients belonged to multiple groups. RR, rifampinresistant; TB, tuberculosis.

757 (11\%) received diagnosis in the first 3 months (2012 Jan 1-2012 Mar 31) $1982(28 \%)$ received diagnosis in last year (2014 Jul 1-2015 Jul 31)

\section{4,247 patients who received RR TB diagnosis within timeframe}

$369(32 \%)$ excluded because differentially affected by decentralization

651 (15\%) only had a diagnostic sample

$84(2 \%)$ were children $<15$ years of age at first sample

2,878 RR TB patients 


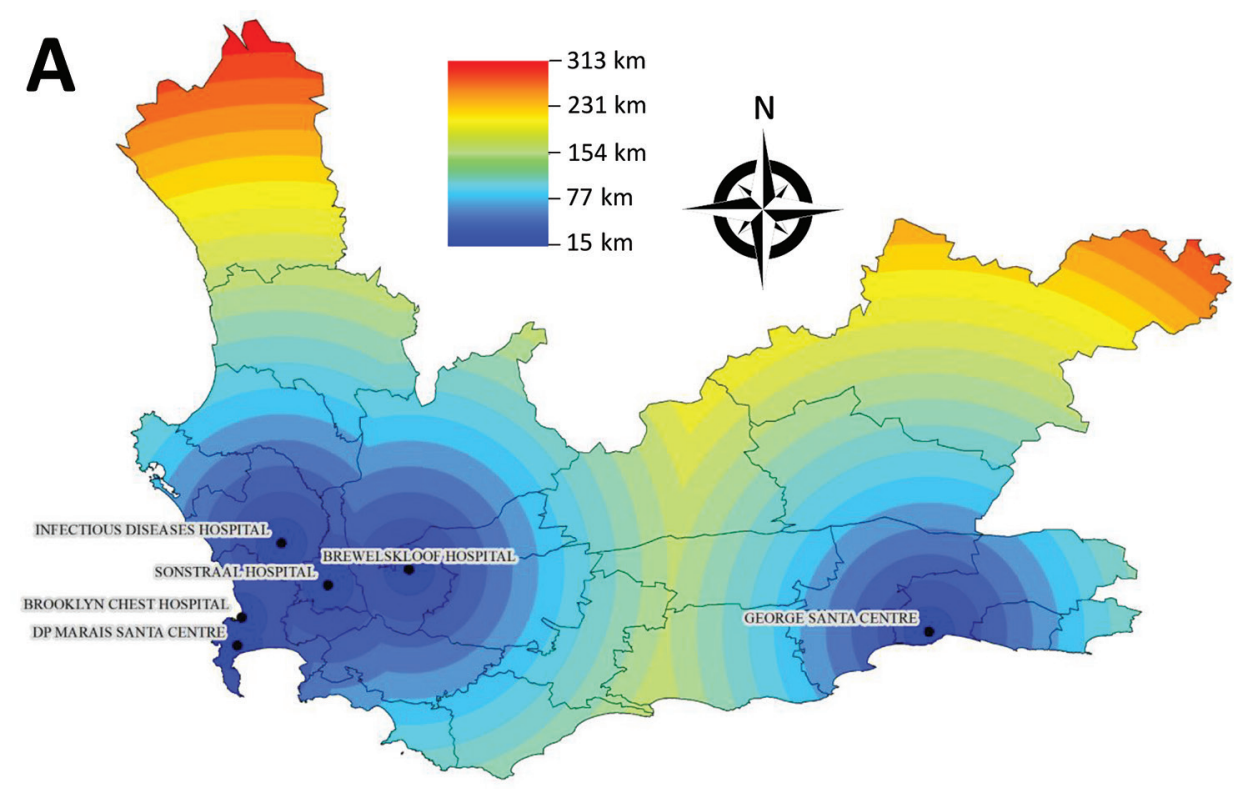

Figure 2. Distances to the nearest tuberculosis healthcare facility, Western Cape Province, South Africa. A) Distance to nearest specialized TB hospital. B) Distance to nearest facility of any type: TB hospital, clinic, or non-TB hospital that was visited by patients in this study during 2012-2015. TB, tuberculosis.

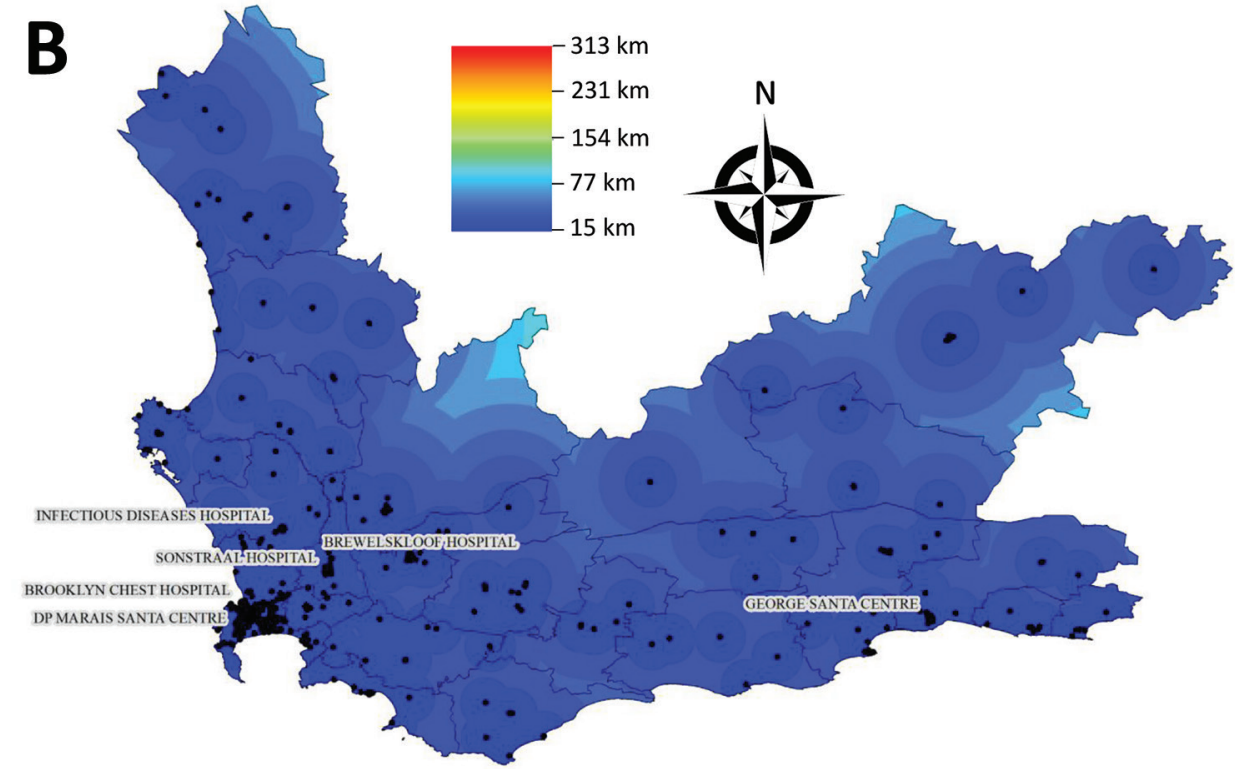

\section{Decentralization Analysis}

The national decentralization policy stated that clinically stable patients with no SLD resistance could initiate treatment at local hospitals and clinics designated as decentralized treatment initiation sites (2). According to this policy, although a small proportion of patients would still be hospitalized for clinical or psychosocial reasons, most patients with RR TB would be treated outside specialized TB hospitals. In addition, hospitalized patients would have shorter hospital stays (2).

We first summarized cohort characteristics regarding sex, age, TB type, type of facility submitting the initial RR TB sample, smear status, number of visits, and time in care. To assess decentralization implementation, we calculated the percentage of patients with $\geq 1$ sample submitted from a TB hospital $\leq 1$ year after diagnosis; we stratified these results by facility type (i.e., TB hospital, non-TB hospital, clinic). We calculated the percentage of patients who transitioned to care outside a TB hospital (i.e., patients who submitted samples from a non-TB hospital or clinic $\leq 3$ months after their most recent sample from a TB hospital). For these patients, we estimated duration of TB hospitalization as the time between the date of the first sample submitted from the TB hospital to the midpoint between the most recent sample submitted from the TB hospital and the date 
of the first subsequent sample submitted from a clinic or non-TB hospital.

We then used simple linear regression to estimate temporal trends of all outcomes by quarter (i.e., 3-month period) of initial RR TB sample during April 2012-June 2014, for a total of 9 quarters. We ran 2 models for each outcome: 1 stratified by diagnosis location and 1 combined model with an interaction term to assess the differences in trend between locations. In addition, we used multivariable logistic regression to test the association between whether or not a patient submitted a sample from a TB hospital and quarter of initial RR TB sample adjusting for sex, age (15-34, 35-54, $\geq 55$ years of age), TB type (pulmonary, extrapulmonary, both), smear status within 1 month of initial RR TB sample, and number of visits $\leq 1$ year after diagnosis. For this analysis only, we excluded patients missing data on age, sex, or both.

One decentralization goal was to enable treatment closer to patients' homes (2). We calculated the percentage of patients that had samples from $\geq 2 \mathrm{fa}-$ cilities, indicating movement between facilities. To estimate travel distance without home addresses, we calculated the total Euclidean distance between all facilities from which a patient submitted samples during the first year after diagnosis. For multiple visits, we counted distances multiple times. Because the number of visits could affect the total distance between facilities, we also determined each patient's number of visits in the first year after diagnosis. We then controlled for the number of visits by calculating the median distance between facilities visited consecutively for each patient. We used linear regressions to assess temporal trends in these travel outcomes.

We stratified analyses by whether patients' initial RR TB samples were from Cape Town or outside Cape Town (i.e., the rest of Western Cape) to identify differential implementation of decentralization. To demonstrate the potential travel benefit for patients receiving RR TB treatment in a clinic or local hospital compared with a specialized TB hospital, we mapped the distance to the nearest TB hospital from anywhere in the province and compared this distance to the distance to the nearest facility of any kind that submitted samples recorded in this study (Figure 2). We used $R$ version 3.6.1 (16) for analyses and ArcMap version

\begin{tabular}{|c|c|c|c|c|}
\hline Characteristic $†$ & Overall, $n=2,878$ & $\begin{array}{c}\text { Cape Town, } \mathrm{n}= \\
1,878\end{array}$ & $\begin{array}{l}\text { Outside Cape Town } \\
n=1,000\end{array}$ & $p$ valuef \\
\hline Sex§ & & & & 0.32 \\
\hline $\mathrm{F}$ & $1,245(43.4)$ & $825(44.1)$ & $420(42.0)$ & \\
\hline $\mathrm{M}$ & $1,626(56.6)$ & $1,047(55.9)$ & 579 (58.0) & \\
\hline Age group, yT & & & & $<0.01$ \\
\hline $15-34$ & $1,420(50.1)$ & $978(53.0)$ & $442(44.9)$ & \\
\hline $35-54$ & $1,232(43.5)$ & $761(41.2)$ & $471(47.8)$ & \\
\hline$\geq 55$ & $180(6.4)$ & $108(5.8)^{\prime}$ & $72(7.3)$ & \\
\hline Type of TB & & & & 0.72 \\
\hline Pulmonary only & 2,685 (93.3) & $1,747(93.0)$ & $938(93.8)$ & \\
\hline Extrapulmonary only & $70(2.4)$ & $47(2.5)$ & $23(2.3)$ & \\
\hline Both & $123(4.3)$ & $84(4.5)$ & $39(3.9)$ & \\
\hline \multicolumn{4}{|c|}{ Results of closest smear within $30 \mathrm{~d}$ of first RR TB-positive sample } & 0.93 \\
\hline Negative & $1,396(48.5)$ & $913(48.6)$ & $483(48.3)$ & \\
\hline Scanty positive & $310(10.8)$ & $202(10.8)$ & $108(10.8)$ & \\
\hline Positive + & $262(9.1)$ & $178(9.5)$ & $84(8.4)$ & \\
\hline Positive ++ & $181(6.3)$ & $118(6.3)$ & $63(6.3)$ & \\
\hline Positive +++ & $499(17.3)$ & $321(17.1)$ & $178(17.8)$ & \\
\hline Unknown & $230(8.0)$ & $146(7.8)$ & $84(8.4)$ & \\
\hline \multicolumn{4}{|l|}{ Setting of first RR TB-positive result } & $<0.01$ \\
\hline TB hospital & $103(3.6)$ & $43(2.3)$ & $60(6.0)$ & \\
\hline Clinic & $2,361(82.0)$ & $1,554(82.7)$ & $807(80.7)$ & \\
\hline Non-TB hospital & $414(14.4)$ & $281(15.0)$ & $133(13.3)$ & \\
\hline $\begin{array}{l}\text { Median time in care }{ }^{\star *} \text { in first year after RR TB } \\
\text { diagnosis, mos (IQR) }\end{array}$ & $11(5-12)$ & $11(5-12)$ & $11(6-12)$ & $<0.01 \#$ \\
\hline $\begin{array}{l}\text { Median number of visits } † \dagger \text { in the first year after RR } \\
\text { TB diagnosis, (IQR) }\end{array}$ & $9(5-12)$ & $8(4-12)$ & $10(5-12)$ & $<0.01 \#$ \\
\hline \multicolumn{5}{|c|}{ 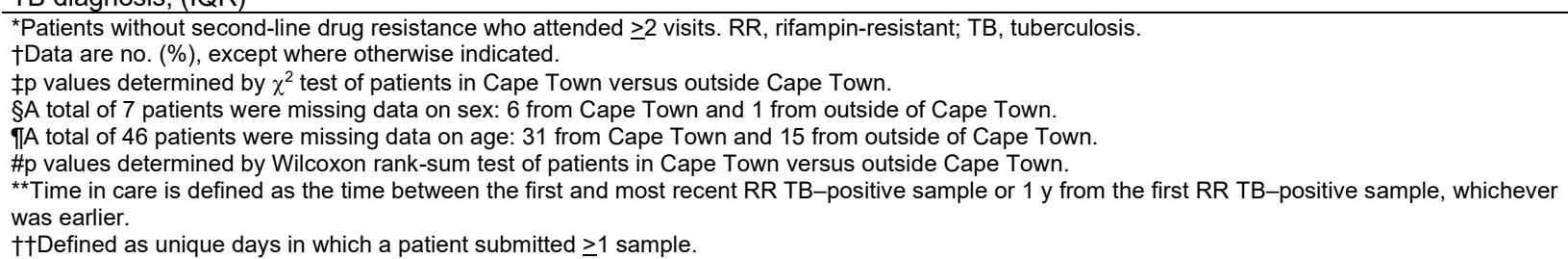 } \\
\hline
\end{tabular}


Table 2. Magnitude and duration of hospitalization and movement of patients with RR TB, Western Cape, South Africa, 2012-2014*

\begin{tabular}{|c|c|c|c|c|}
\hline Description & $\begin{array}{c}\text { Overall, } \\
\mathrm{n}=2,878\end{array}$ & $\begin{array}{c}\text { Cape Town, } \\
n=1,878\end{array}$ & $\begin{array}{l}\text { Outside Cape } \\
\text { Town, } n=1,000\end{array}$ & $\mathrm{p}$ value \\
\hline $\begin{array}{l}\text { Hospitalization in TB hospital, no. }(\%) \\
\text { No. patients with } \geq 1 \text { sample from a specialized TB hospital in the } \\
\text { first year after RR TB diagnosis }\end{array}$ & $1,228(42.7)$ & $545(29.0)$ & $683(68.3)$ & $<0.01$ \\
\hline $\begin{array}{l}\text { Moved to care outside TB hospital, no. (\%) } \\
\text { No. patients with a sample from a TB hospital who had a } \\
\text { subsequent sample from a non-TB hospital }<3 \text { mo after the most } \\
\text { recent sample in the TB hospital }\end{array}$ & 837 (68.2) & $317(58.2)$ & $520(76.1)$ & $<0.01$ \\
\hline $\begin{array}{l}\text { Median length of TB hospital stay, d (IQR) } \\
\text { Median hospitalization period of patients who moved to care outside } \\
\text { of a TB hospital in the first year after RR TB diagnosis }\end{array}$ & $99(61-136)$ & $79(50-118)$ & $108(72-144)$ & $<0.01 \ddagger$ \\
\hline $\begin{array}{l}\text { Any movement, no. (\%) } \\
\text { No. patients who had samples from } \geq 2 \text { different facilities in first year } \\
\text { after RR TB diagnosis }\end{array}$ & 1,765 (61.3) & $1,012(53.9)$ & $753(75.3)$ & $<0.01$ \\
\hline $\begin{array}{l}\text { Median no. of visits (IQR) } \\
\text { No. unique days with } \geq 1 \text { laboratory sample in the first year after RR } \\
\text { TB diagnosis }\end{array}$ & $9(5-12)$ & $8(4-12)$ & $10(5-12)$ & $<0.01 \ddagger$ \\
\hline $\begin{array}{l}\text { Median total distance, } \mathrm{km}(\mathrm{IQR}) \\
\text { Total Euclidian distance between all facilities visited by each patient } \\
\text { in the first year after RR TB diagnosis }\end{array}$ & $4.4(0.0-41)$ & $1.5(0.0-20)$ & $46.0(0.2-122)$ & $<0.01 \ddagger$ \\
\hline $\begin{array}{l}\text { Median distance between consecutive visits, km (IQR) } \\
\text { Median distance between facilities visited consecutively by each } \\
\text { patient in the first year after RR TB diagnosis }\end{array}$ & $2.7(0.0-19.8)$ & $1.4(0.0-12.2)$ & $24.0(0.2-64.8)$ & $<0.01 \ddagger$ \\
\hline
\end{tabular}

10.6 (Environmental Systems Research Institute, Inc., https:/ / desktop.arcgis.com) for mapping.

\section{Results}

\section{Cohort Description}

After excluding ineligible patients, we analyzed a cohort of 2,878 patients who received a diagnosis of RR TB during April 1, 2012-June 30, 2014 (Figure 1). The exclusions included 651 (15.3\%) patients with only a diagnostic sample recorded $(14.0 \%$ of patients in Cape Town and $17.7 \%$ outside Cape Town; Appendix Table 1). Of the 2,878 patients, 1,878 (65\%) submitted their initial RR TB sample from Cape Town and 1,000 (35\%) from outside Cape Town. The mean age was 36 years (SD \pm 12 years), and $57 \%$ were men. Most (93\%) patients had RR TB detected from sputum or lung samples, suggesting pulmonary disease, and $49 \%$ had negative smear microscopy results when RR TB was detected (Table 1).

\section{Samples from Specialized TB Hospitals}

In total, 2,361 (82\%) patients submitted initial RR TB samples from clinics, 414 (14\%) from non-TB hospitals, and 103 (4\%) from TB hospitals. Although only $4 \%$ of patients submitted their initial RR TB sample from a TB hospital, 1,228 (43\%) patients submitted $\geq 1$ sample from a TB hospital $\leq 1$ year after diagnosis. In particular, $894(38 \%)$ patients who submitted their initial sample from a clinic and 231 (56\%) who submitted their initial sample from a non-TB hospital submitted $\geq 1$ additional sample from a TB hospital (Appendix Table 2). Patients in Cape Town were significantly less likely to submit a sample from a TB hospital than patients outside Cape Town (29\% vs. $68 \% ; \mathrm{p}<0.01)$. Of the 545 patients from Cape Town who submitted a TB hospital sample, 317 (58\%) transitioned to care outside of the TB hospital compared with $520(76 \%)$ of the 683 patients outside Cape Town $(p<0.01)$. We estimated that the median first TB hospital stay for those who transitioned to care outside of the TB hospital was 79 days (interquartile range [IQR] 50-118 days) in Cape Town and 108 days (IQR 72-144 days) outside Cape Town (Table 2).

In Cape Town, the percentage of patients who submitted a TB hospital sample in the first year on average decreased by 1 percentage point $(95 \% \mathrm{CI}$ $0.2 \%-1.7 \% ; p=0.02)$ per quarter, representing a 9 percentage point decrease during the study period; we observed no statistically significant trend outside Cape Town (Table 3). During the study period, the percentage of patients who transitioned to care outside of a TB hospital stayed constant in and outside Cape Town. In Cape Town, the estimated first TB hospital stay duration decreased by 3.6 days per quarter (95\% CI -8.7 to 1.5 days; $p=0.14$ ), for a total decrease of 32 days during the study. Outside Cape Town, the duration stayed constant (Table 3; Figure 3). Visual inspection of all trends indicated that linear trends were appropriate. 
Table 3. Linear temporal trends in magnitude and duration of movement for adult patients with RR TB, Western Cape, South Africa, 2012-2014*

\begin{tabular}{|c|c|c|c|c|c|c|c|}
\hline \multirow[b]{2}{*}{ Description } & \multicolumn{2}{|c|}{ Overall, $n=2,878$} & \multicolumn{2}{|c|}{ Cape Town, $n=1,878$} & \multicolumn{2}{|c|}{$\begin{array}{l}\text { Outside Cape Town, } \\
n=1,000\end{array}$} & \multirow[b]{2}{*}{$\begin{array}{l}\text { Interaction } \\
\mathrm{p} \text { value }\end{array}$} \\
\hline & $\begin{array}{c}\text { Slope } \\
(95 \% \mathrm{Cl})\end{array}$ & $\begin{array}{c}p \\
\text { value }\end{array}$ & $\begin{array}{c}\text { Slope } \\
(95 \% \mathrm{Cl})\end{array}$ & $\begin{array}{c}\mathrm{p} \\
\text { value }\end{array}$ & $\begin{array}{c}\text { Slope } \\
(95 \% \mathrm{Cl})\end{array}$ & $\begin{array}{c}\mathrm{p} \\
\text { value }\end{array}$ & \\
\hline $\begin{array}{l}\text { Hospitalization in TB hospital, no. (\%) } \\
\text { No. patients with } \geq 1 \text { sample from a } \\
\text { specialized TB hospital in the first year after } \\
\text { RR TB diagnosis }\end{array}$ & $\begin{array}{c}-0.4 \\
(-1.2 \text { to } 0.5)\end{array}$ & 0.33 & $\begin{array}{c}-1.0 \\
(-1.7 \text { to }-0.2)\end{array}$ & 0.02 & $\begin{array}{c}1.1 \\
(-0.9 \text { to } 3.1)\end{array}$ & 0.23 & 0.03 \\
\hline $\begin{array}{l}\text { Moved to care outside TB hospital, no. (\%) } \\
\text { No. patients with a sample from a TB } \\
\text { hospital who had a subsequent sample } \\
\text { from a non-TB hospital }<3 \text { mo after the } \\
\text { most recent sample in the TB hospital }\end{array}$ & $\begin{array}{c}0.2 \\
(-0.9 \text { to } 1.3)\end{array}$ & 0.69 & $\begin{array}{c}0.1 \\
(-1.3 \text { to } 1.6)\end{array}$ & 0.84 & $\begin{array}{c}-0.01 \\
(-1.8 \text { to } 1.8)\end{array}$ & 0.99 & 0.89 \\
\hline $\begin{array}{l}\text { Median length of TB hospital stay, d (IQR) } \\
\text { Median hospitalization period of patients } \\
\text { who moved to care outside of a TB hospital } \\
\text { in the first year after RR TB diagnosis }\end{array}$ & $\begin{array}{c}-1.5 \\
(-5.7 \text { to } 2.6)\end{array}$ & 0.42 & $\begin{array}{c}-3.6(-8.7 \text { to } \\
1.5)\end{array}$ & 0.14 & $\begin{array}{c}-0.28 \\
(-4.3 \text { to } 3.7)\end{array}$ & 0.87 & 0.24 \\
\hline $\begin{array}{l}\text { Any movement, no. }(\%) \\
\text { No. patients who had samples from } \geq 2 \\
\text { different facilities in first year after RR TB } \\
\text { diagnosis }\end{array}$ & $\begin{array}{c}-0.5 \\
(-1.2 \text { to } 0.3)\end{array}$ & 0.19 & $\begin{array}{c}-0.9 \\
(-1.7 \text { to }-0.06)\end{array}$ & 0.04 & $\begin{array}{c}0.5 \\
(-1.2 \text { to } 2.3)\end{array}$ & 0.50 & 0.10 \\
\hline $\begin{array}{l}\text { Median no. of visits (IQR) } \\
\text { No. unique days with } \geq 1 \text { laboratory sample } \\
\text { in the first year after RR TB diagnosis }\end{array}$ & $\begin{array}{c}0.04 \\
(-0.01 \text { to } 0.1)\end{array}$ & 0.12 & $\begin{array}{c}0.0 \\
(-0.2 \text { to } 0.2)\end{array}$ & $>0.99$ & $\begin{array}{c}0.1 \\
(-0.01 \text { to } 0.2)\end{array}$ & 0.06 & 0.22 \\
\hline $\begin{array}{l}\text { Median total distance, } \mathrm{km} \text { (IQR) } \\
\text { Total Euclidian distance between all } \\
\text { facilities visited by each patient in the first } \\
\text { year after RR TB diagnosis }\end{array}$ & $\begin{array}{c}-0.1 \\
(-0.4 \text { to } 0.2)\end{array}$ & 0.43 & $\begin{array}{c}-0.3 \\
(-0.5 \text { to }-0.01)\end{array}$ & 0.04 & $\begin{array}{c}4.7 \\
(-1.3 \text { to } 10.6)\end{array}$ & 0.10 & 0.07 \\
\hline $\begin{array}{l}\text { Median distance between consecutive } \\
\text { visits, } \mathrm{km} \text { (IQR) } \\
\text { Median distance between facilities visited } \\
\text { consecutively by each patient in the first } \\
\text { year after RR TB diagnosis }\end{array}$ & $\begin{array}{c}-0.06 \\
(-0.2 \text { to } 0.04)\end{array}$ & 0.21 & $\begin{array}{c}-0.18 \\
(-0.4 \text { to }-0.02)\end{array}$ & 0.07 & $\begin{array}{c}2.5 \\
(-0.5 \text { to } 5.6)\end{array}$ & 0.09 & 0.05 \\
\hline
\end{tabular}

We included 2,831 patients in the individuallevel multivariable logistic regression analysis and adjusted for number of visits. In Cape Town, the odds of submitting a sample from a TB hospital decreased by $5 \%$ per quarter $(p=0.02)$; outside Cape Town, we found no statistically significant association. Outside Cape Town, increasing smear grade (i.e., scanty,,,++++++ ) was associated with increasing odds of submitting a sample from a TB hospital (Table 4).

\section{Distance Traveled}

In the first year after diagnosis, patients with RR TB had samples submitted from 315 different facilities: 268 clinics, 41 non-TB hospitals, and 6 TB hospitals (Appendix Table 3). Most patient movements between different facilities involved a TB hospital (Figure 4). A total of 1,765 (61\%) patients submitted samples from $\geq 2$ different facilities. Patients outside Cape Town were more likely to transition between facilities than those in Cape Town $(75 \%$ vs. $54 \%$; $<<0.01)$ (Table 2). Overall, the median Euclidean distance traveled between facilities was $4.4 \mathrm{~km}$ (IQR 0-41 km). The median distance traveled was significantly shorter in Cape Town $(1.5 \mathrm{~km}, \mathrm{IQR} 0-20 \mathrm{~km})$ than outside Cape Town $(46 \mathrm{~km}, \mathrm{IQR} \quad 0.2-122 \mathrm{~km}$; $\mathrm{p}<0.01)$. This disparity remained after controlling for the number of visits per patient (Table 2).

In Cape Town, the percentage of patients who transitioned between facilities decreased by 0.9 percentage points per quarter $(95 \%$ CI $0.1 \%-1.7 \%$; $p=$ 0.04 ) and the total distance between all facilities visited decreased by $0.3 \mathrm{~km}$ per quarter (95\% CI 0.01-0.5 $\mathrm{km} ; \mathrm{p}=0.04)$. However, outside Cape Town, this distance increased by $4.7 \mathrm{~km}$ each quarter $(95 \% \mathrm{CI}$ -1.3 to $10.6 \mathrm{~km} ; \mathrm{p}=0.10)$. We observed no statistically significant change in median number of visits. Trends in median distance between consecutive visits were consistent with total distance trends (Table 3; Figure 3). In Cape Town, the distances to the nearest TB hospital compared with the nearest clinic or non-TB hospital were similar. Outside Cape Town, clinics and non-TB hospitals were often much closer than the nearest TB hospital (Figure 2). 


\section{Discussion}

We used routinely collected laboratory data from Western Cape, South Africa to evaluate implementation of a national policy to decentralize MDR/RR TB care. Patients with RR TB in Cape Town facilities were less likely to have samples submitted from a TB hospital than patients outside Cape Town (29\% vs. $68 \%, \mathrm{p}<0.01$ ), suggesting that persons in Cape Town were less likely to be hospitalized for RR TB. In addition, the percentage of patients who were likely hospitalized decreased significantly in Cape Town but not outside Cape Town. In Cape Town, the estimated average duration of TB hospitalization was nearly a month shorter and decreased over time compared with stays outside Cape Town, where duration remained constant.

These findings suggest that after the decentralization policy was implemented, more decentralization occurred in Cape Town than outside Cape Town. Loveday et al. (9) showed that treatment outcomes across decentralized sites in KwaZulu-Natal varied greatly and were highly influenced by health system performance. Health system factors such as long distances between facilities and limited provision of resources, training, and support from TB hospitals might have slowed decentralized care uptake in more rural areas. Furthermore, the large distances between patients in rural areas posed challenges to in-home medication administration. Additional outreach efforts such as mobile clinics have facilitated RR TB diagnosis. However, because mobile clinics might not be staffed in the same location each day, they are unable to administer SLDs, suggesting that broader access to new oral second-line TB drugs is needed in these settings (17).

Although the national policy change was introduced in 2011, Cape Town subdistricts had already begun decentralizing RR TB care after the success of the pilot program in Khayelitsha in $2009(2,4)$. Our findings are consistent with previous work showing substantial challenges to healthcare access in rural areas of South Africa (18-21). The limited timeframe (2012-2015) of our study might have hindered our ability to detect slow changes in referral patterns outside Cape Town. However, Hill et al. (18) showed that in 2016, Cape Town patient travel patterns were still more consistent with a decentralized model than those elsewhere in the Western Cape.

In our study, patients outside Cape Town traveled 30 times further than patients in Cape Town (46 $\mathrm{km}$ vs. $1.5 \mathrm{~km}$ ). Over the study period, travel distance decreased significantly for patients in Cape Town and increased for those outside Cape Town. This pattern of longer travel distances for healthcare in more rural

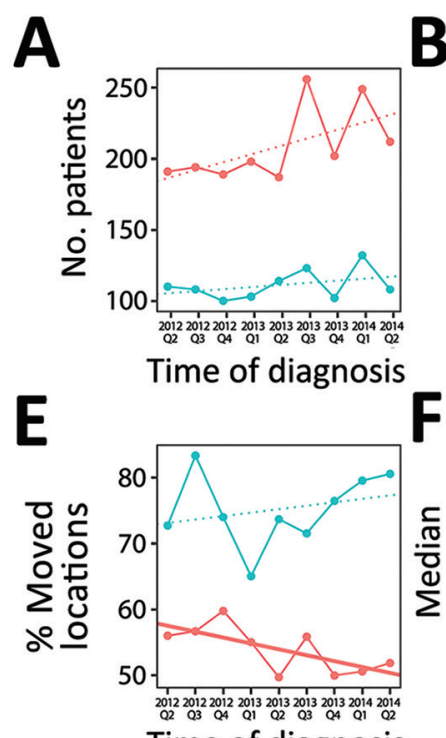

Time of diagnosis

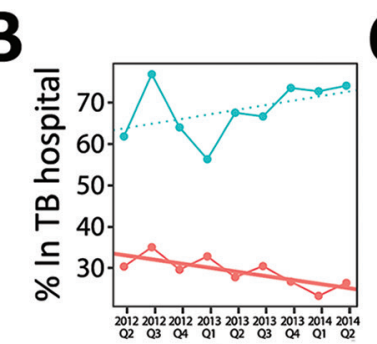

Time of diagnosis

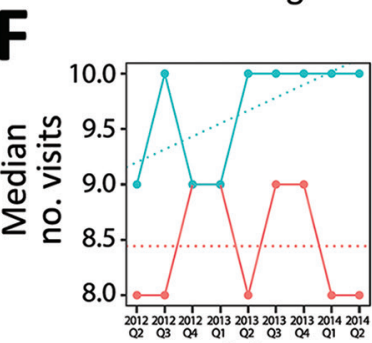

Time of diagnosis

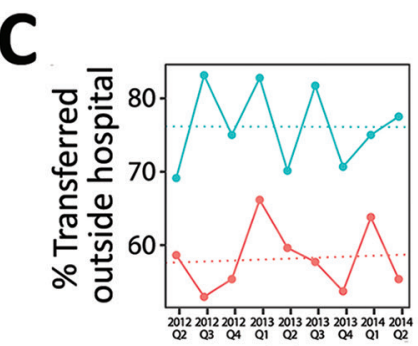

Time of diagnosis

\section{G}

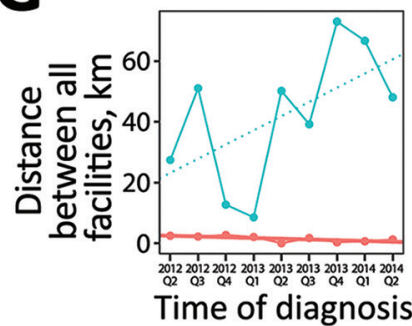

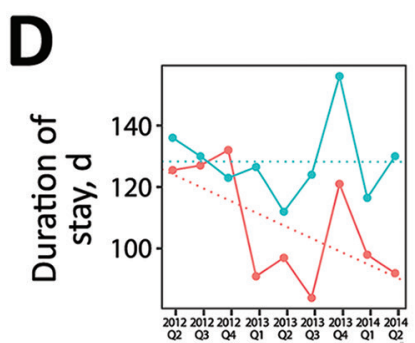

Time of diagnosis
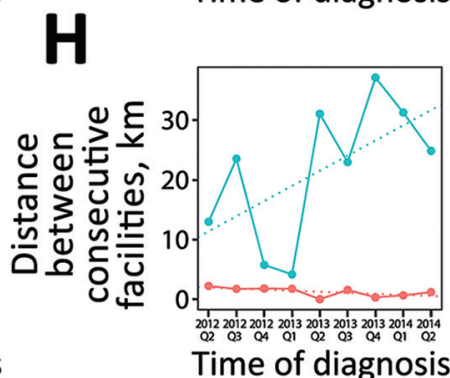

Figure 3. Linear time trends in magnitude and duration of movement for adult patients with RR TB, Western Cape, South Africa, 20122014. Patients did not have second-line drug resistance and attended $\geq 2$ clinic visits. Linear regression trendlines are colored based on district of diagnosis (red indicates Cape Town; blue indicates other districts) and styled based on significance (solid line indicates $p<0.05$; dotted line indicates $p \geq 0.05$ ). A) Number of patients diagnosed with RR TB. B) Percentage of patients who submitted a sample from a TB hospital $\leq 1$ year after diagnosis. C) Percentage of patients who transitioned to care outside a TB hospital. D) Median duration of first stay in a TB hospital. E) Percentage of patients who transitioned to different facilities. F) Median number of visits in which patient submitted $\geq 1$ sample. G) Median total Euclidean distance traveled between locations. H) Median Euclidean distance between consecutive visits. RR, rifampin-resistant; TB, tuberculosis. 
Table 4. Multivariable logistic regression for factors associated with sample submitted from a TB hospital $\leq 1$ y after diagnosis of RR TB, Western Cape, South Africa, 2012-2014*

\begin{tabular}{|c|c|c|c|c|c|c|}
\hline \multirow{2}{*}{ Characteristic } & \multicolumn{2}{|c|}{ Overall, $n=2,831$} & \multicolumn{2}{|c|}{ Cape Town, $\mathrm{n}=1,846$} & \multicolumn{2}{|c|}{ Outside Cape Town, $\mathrm{n}=985$} \\
\hline & OR $(95 \% \mathrm{Cl})$ & $\mathrm{p}$ value & OR $(95 \% \mathrm{Cl})$ & $p$ value & $\mathrm{OR}(95 \% \mathrm{Cl})$ & $p$ value \\
\hline \multicolumn{7}{|l|}{ Location } \\
\hline Cape Town & Referent & & Referent & & Referent & \\
\hline Other & $5.7(4.8-6.8)$ & $<0.01$ & NA & & NA & \\
\hline \multicolumn{7}{|l|}{ Sex } \\
\hline $\mathrm{F}$ & Referent & & Referent & & Referent & \\
\hline M & $1.2(1.0-1.4)$ & 0.03 & $1.2(1.0-1.5)$ & 0.07 & $1.2(0.9-1.6)$ & 0.27 \\
\hline \multicolumn{7}{|l|}{ Age, y } \\
\hline $15-34$ & Referent & & Referent & & Referent & \\
\hline $35-54$ & $1.1(0.9-1.3)$ & 0.43 & $1.2(0.9-1.5)$ & 0.14 & $0.9(0.7-1.3)$ & 0.55 \\
\hline$\geq 55$ & $0.8(0.6-1.2)$ & 0.24 & $1.0(0.6-1.6)$ & 0.95 & $0.6(0.3-1.0)$ & 0.05 \\
\hline \multicolumn{7}{|l|}{ Type of TB } \\
\hline Pulmonary only & Referent & & Referent & & Referent & \\
\hline Extrapulmonary only & $1.0(0.5-1.7)$ & 0.98 & $0.8(0.4-1.7)$ & 0.63 & $1.3(0.5-3.5)$ & 0.53 \\
\hline Both & $2.7(1.8-4.2)$ & $<0.01$ & $3.7(2.3-5.9)$ & $<0.01$ & $1.1(0.5-2.4)$ & 0.85 \\
\hline \multicolumn{7}{|c|}{ Results of most recent smear from $\leq 30 \mathrm{~d}$ of first RR TB-positive sample } \\
\hline Negative & Referent & & Referent & & Referent & \\
\hline Scanty positive & $1.4(1.0-1.8)$ & 0.03 & $1.7(1.2-2.4)$ & $<0.01$ & $1.0(0.6-1.6)$ & $>0.99$ \\
\hline Positive + & $1.5(1.1-2.1)$ & $<0.01$ & $1.6(1.1-2.2)$ & 0.02 & $1.5(0.9-2.8)$ & 0.16 \\
\hline Positive ++ & $1.8(1.3-2.5)$ & $<0.01$ & $1.5(1.0-2.3)$ & 0.06 & $3.0(1.5-6.4)$ & $<0.01$ \\
\hline Positive +++ & $2.1(1.7-2.7)$ & $<0.01$ & $1.9(1.4-2.5)$ & $<0.01$ & $3.5(2.2-5.8)$ & $<0.01$ \\
\hline Unknown & $1.2(0.9-1.7)$ & 0.19 & $1.2(0.8-1.9)$ & 0.29 & $1.2(0.7-2.1)$ & 0.56 \\
\hline Quarter of RR TB diagnosis $†$ & $\begin{array}{c}0.98(0.95- \\
1.02)\end{array}$ & 0.29 & $0.95(0.92-0.99)$ & 0.02 & $1.04(0.98-1.10)$ & 0.20 \\
\hline
\end{tabular}

areas of South Africa is well-documented (18-20). Although rural areas face more challenges to decentralization, the spread of local facilities throughout Western Cape indicates the potential for a reduction in travel distances for patients outside Cape Town (12). Shorter travel distances decrease treatment-related challenges for patients, enable local clinics to provide more patient support, and decrease risk for transmission during travel (22).

Although NHLS data are reliable for assessing aspects of TB and HIV care, its use introduces limitations to our study $(18,23-29)$. These data lack information regarding treatment initiation, hospitalization, admission and discharge dates, and treatment outcomes. We therefore focused on where patients submitted samples and assumed repeat samples implied treatment prescription and monitoring $(29,30)$. We also assumed that providing a sample at a TB hospital implied inpatient admission, which we believe is reasonable given that TB hospitals in the Western Cape only provide inpatient care (12). To focus on patients most likely to have started and continued RR TB treatment, we excluded patients without subsequent samples after the initial RR TB sample. However, this criterion might have excluded patients with extrapulmonary TB or those unable or unwilling to produce sputum samples. Furthermore, we could not account for patients who moved or transferred care to other provinces.
Without admission and discharge dates, our TB hospital stay duration estimate is a proxy for true hospital stay. In addition, without residential addresses, our distance traveled measure is a proxy for total travel distance. We also measured simple Euclidean distance between facilities, which might not reflect true traveling distance. Despite these limitations, the relative differences between Cape Town and outside Cape Town and the time trends should represent differences and trends in true hospital stays and travel distances.

Our study is also limited by its timeframe (20122015), which does not extend before the decentralization policy or to the present day, and by our inability to attribute causality between the decentralization policy and our estimated measures. Therefore, these results reflect patterns observed during early policy implementation and are a proof-of-concept that routinely collected laboratory data can be used to assess care patterns following policy implementation. However, other interventions, such as the introduction of GeneXpert, occurred in 2011 and 2012, which might also have affected TB diagnostic use and care. Our results might not be generalizable to all of South Africa because the Western Cape has more decentralized TB care units than other provinces (12), and Hill et al. (18) showed that in 2016 patients in Eastern Cape and KwaZulu-Natal had more centralized care patterns than patients in Western Cape. 
The benefits of the decentralization of MDR/RR TB care have been documented in South Africa and elsewhere. In Khayelitsha, Cox et al. (5-7) found that decentralized care resulted in higher case detection, better outcomes, and lower costs. In KwaZulu-Natal, Loveday et al. (9-11) observed that decentralized sites had shorter time to treatment initiation and higher cul- ture conversion rates; however, outcomes were poorer where decentralized services were not integrated into existing services. These studies concluded that regular monitoring and support were needed to optimize outcomes (9-11). Although Western Cape was the forerunner for implementing community-based MDR/RR TB care in South Africa, we have shown that locations

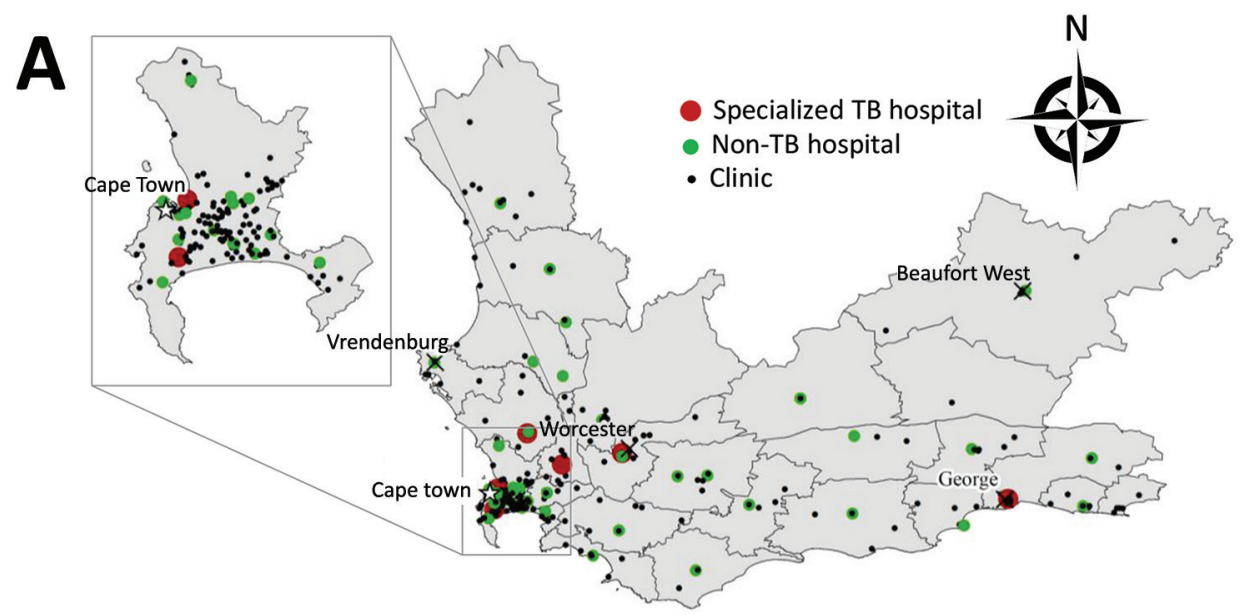

Figure 4. Healthcare facilities visited and movements between hospitals by patients in RR TB cohort, Western Cape Province, South Africa, 2012-2014. Inset maps show the Cape Town Metropole. A) All healthcare facilities visited $\leq 1$ y after diagnosis. B) All movements made $\leq 1$ y after diagnosis that involved TB hospitals. C) All movements made $\leq 1$ y after diagnosis that did not involve a TB hospital. RR, rifampinresistant; TB, tuberculosis.
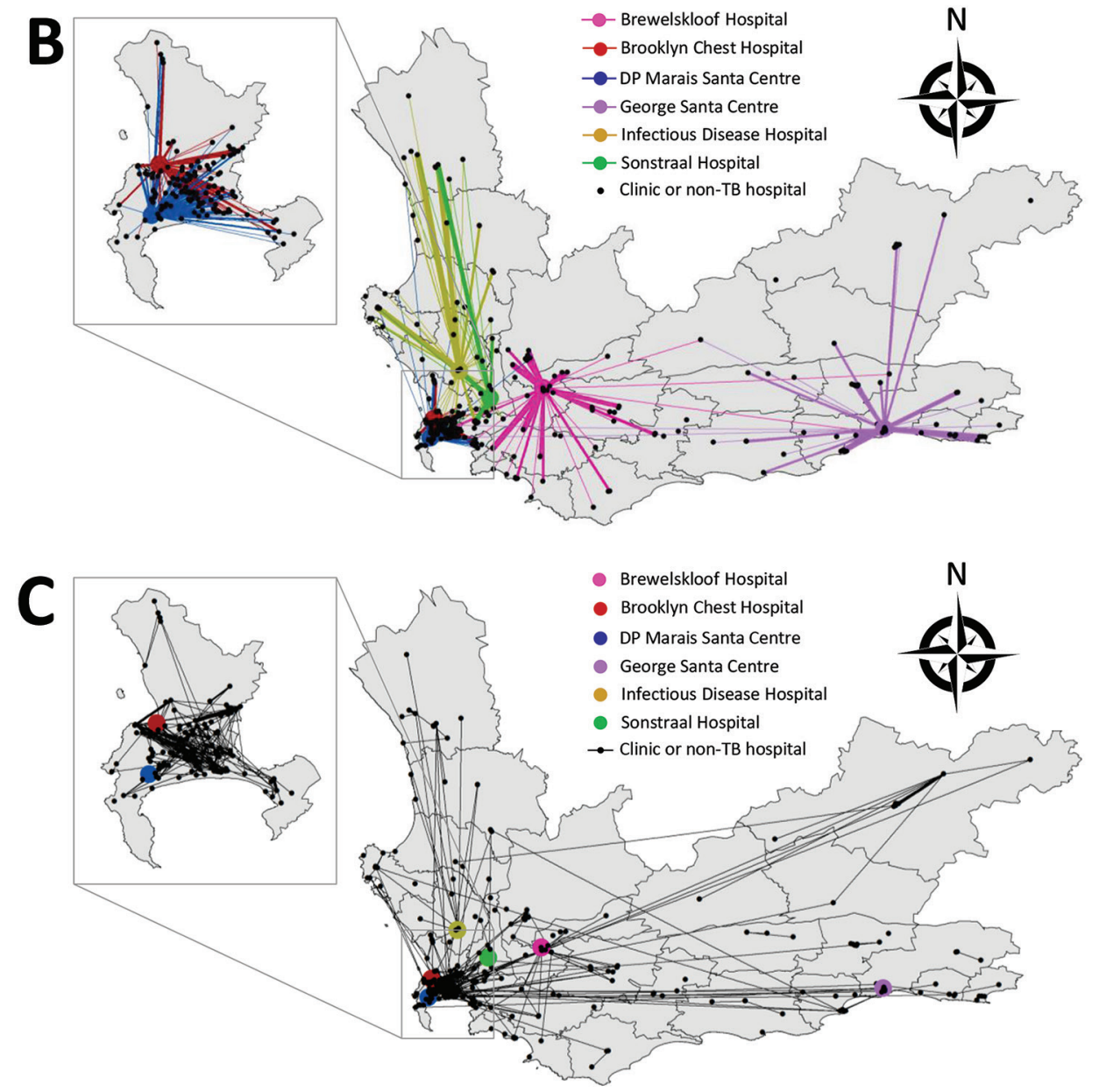
outside Cape Town, and likely rural areas in general, need more support for implementing these policies $(12,18)$. We have demonstrated a proof-of-concept that laboratory data can be used to assess policy implementation. As we work toward TB elimination, we must maximize our use of available, routinely collected data as a cost-effective, rapid method for evaluating policy implementation. Laboratory data can contribute to evidence-based expansion of policies to improve TB treatment and reduce incidence.

S.V.L. and H.E.J. were funded by the US National Institutes of Health (NIH) (grant no. NIH R03AI144335). S.V.L. was funded by the US NIH (Interdisciplinary Training grant no. NIHGMS T32GM074905) and the Providence/Boston Center for AIDS Research (grant no. P30AI042853), which is co-funded by the National Institute of Allergy and Infectious Diseases, the National Institute on Aging, the Eunice Kennedy Shriver National Institute of Child Health and Human Development, the National Institute on Drug Abuse, the National Institute of Diabetes and Digestive and Kidney Diseases, the National Institute on Minority Health and Health Disparities, the National Institute of Mental Health, the National Cancer Institute, the National Institute of General Medical Sciences, the National Institute of Dental and Craniofacial Research, and the National Heart, Lung, and Blood Institute. H.E.J. was also funded by the US NIH (grant nos. NIH K01AI102944 and NIH R01AI152126). T.C.B. was funded by NIH (NIH T32DA013911) and the Burroughs Wellcome Fund/ American Society for Tropical Medicine and Hygiene Postdoctoral Fellowship in Tropical Infectious Diseases. K.R.J. was funded by the US NIH (grant nos. K01TW009213, R01AI119037). R.M.W. was supported by the South African Medical Research Council.

\section{About the Author}

Dr. Leavitt is a postdoctoral associate at Boston University, Boston. Her research interests include using laboratory data to study tuberculosis care patterns and developing methods to estimate infectious disease transmission probabilities.

\section{References}

1. World Health Organization. Global tuberculosis report 2019. Geneva: World Health Organization; 2019.

2. National Department of Health. Multi-drug resistant tuberculosis: a policy framework on decentralised and deinstitutionalized management for South Africa. Pretoria (South Africa): National Department of Health; 2011.

3. Evans D, Sineke T, Schnippel K, Berhanu R, Govathson C, Black A, et al. Impact of Xpert MTB/RIF and decentralized care on linkage to care and drug-resistant tuberculosis treatment outcomes in Johannesburg, South Africa. BMC Health Serv Res. 2018;18:973. https://doi.org/10.1186/s12913-018-3762-x
4. Medecins Sans Frontiers. Scaling up diagnosis and treatment of drug-resistant tuberculosis in Khayelitsha, South Africa. 2011 [cited 2020 Apr 15]. http:// www.msfaccess.org/sites/ default/files/MSF_assets/TB/Docs/TB_report_Scaling UpDxTxKhaye_ENG_2011.pdf

5. Cox H, Ramma L, Wilkinson L, Azevedo V, Sinanovic E. Cost per patient of treatment for rifampicin-resistant tuberculosis in a community-based programme in Khayelitsha, South Africa. Trop Med Int Health. 2015;20:1337-45. https:// doi.org/10.1111/tmi.12544

6. Cox H, Hughes J, Daniels J, Azevedo V, McDermid C, Poolman M, et al. Community-based treatment of drugresistant tuberculosis in Khayelitsha, South Africa. Int J Tuberc Lung Dis. 2014;18:441-8. https:/ / doi.org/10.5588/ ijtld.13.0742

7. Cox HS, Daniels JF, Muller O, Nicol MP, Cox V, van Cutsem G, et al. Impact of decentralized care and the Xpert MTB/RIF test on rifampicin-resistant tuberculosis treatment initiation in Khayelitsha, South Africa. Open Forum Infect Dis. 2015;2:ofv014 https:/ / doi.org/10.1093/ ofid/ofv014

8. Evans D, Schnippel K, Govathson C, Sineke T, Black A, Long $\mathrm{L}$, et al. Treatment initiation among persons diagnosed with drug resistant tuberculosis in Johannesburg, South Africa. PLoS One. 2017;12:e0181238. https:/ / doi.org/ 10.1371/journal.pone.0181238

9. Loveday M, Padayatchi N, Wallengren K, Roberts J, Brust JCM, Ngozo J, et al. Association between health systems performance and treatment outcomes in patients co-infected with MDR-TB and HIV in KwaZulu-Natal, South Africa: implications for TB programmes. PLoS One. 2014;9:e94016. https:/ / doi.org/10.1371/journal.pone.0094016

10. Loveday M, Wallengren K, Reddy T, Besada D, Brust JCM, Voce A, et al. MDR-TB patients in KwaZulu-Natal, South Africa: cost-effectiveness of 5 models of care. PLoS One. 2018;13:e0196003. https://doi.org/10.1371/journal. pone. 0196003

11. Loveday M, Wallengren K, Voce A, Margot B, Reddy T, Master I, et al. Comparing early treatment outcomes of MDR-TB in decentralised and centralised settings in KwaZulu-Natal, South Africa. Int J Tuberc Lung Dis. 2012;16:209-15. https:/ / doi.org/10.5588/ijtld.11.0401

12. National Department of Health. Summary report on decentralized and multi-drug resistant tuberculosis services in South Africa. 2017 [cited 2019 Aug 23]. https:/ / tinyurl.com/ Leavitt2021

13. TB Diagnostics Market Analysis Consortium. Market assessment of tuberculosis diagnostics in South Africa, 2012-2013. Int J Tuberc Lung Dis. 2015;19:216-22. https://doi.org/10.5588/ijtld.14.0565

14. National Department of Health. National tuberculosis management guidelines 2014. Pretoria (South Africa): Fishwicks PTA; 2014. p. 28.

15. Fox MP, Bor J, Brennan AT, MacLeod WB, Maskew M, Stevens WS, et al. Estimating retention in HIV care accounting for patient transfers: a national laboratory cohort study in South Africa [Erratum in: PLoS Med. 2018;15:e1002643]. PLoS Med. 2018;15:e1002589. https://doi.org/10.1371/journal.pmed.1002589

16. R Core Team. R: a language and environment for statistical computing. Vienna (Austria): R Foundation for Statistical Computing; 2019 [cited 2020 Apr 15]. https://www.r-project.org/

17. Udwadia Z, Furin J. Quality of drug-resistant tuberculosis care: gaps and solutions [Erratum in: J Clin Tuberc Other Mycobact Dis. 2020;21:100177]. J Clin Tuberc Other 
Mycobact Dis. 2019;16:100101. https://doi.org/10.1016/ j.jctube.2019.100101

18. Hill J, Dickson-Hall L, Grant AD, Grundy C, Black J, Kielmann K, et al. Drug-resistant tuberculosis patient care journeys in South Africa: a pilot study using routine laboratory data. Int J Tuberc Lung Dis. 2020;24:83-91. https:/ /doi.org/10.5588/ijtld.19.0100

19. McLaren ZM, Ardington C, Leibbrandt M. Distance decay and persistent health care disparities in South Africa. BMC Health Serv Res. 2014;14:541. https://doi.org/10.1186/ s12913-014-0541-1

20. Harris B, Goudge J, Ataguba JE, McIntyre D, Nxumalo N, Jikwana $S$, et al. Inequities in access to health care in South Africa. J Public Health Policy. 2011;32:S102-23. https://doi.org/10.1057/jphp.2011.35

21. van Rensburg HCJ. South Africa's protracted struggle for equal distribution and equitable access - still not there. Hum Resour Health. 2014;12:26. https:/ / doi.org/10.1186/ 1478-4491-12-26

22. Kapwata T, Morris N, Campbell A, Mthiyane T, Mpangase P, Nelson KN, et al. Spatial distribution of extensively drug-resistant tuberculosis (XDR TB) patients in KwaZulu-Natal, South Africa. PLoS One. 2017;12:e0181797. https://doi.org/10.1371/journal.pone.0181797

23. Bassett IV, Huang M, Cloete C, Candy S, Giddy J, Frank SC, et al. Using national laboratory data to assess cumulative frequency of linkage after transfer to community-based HIV clinics in South Africa. J Int AIDS Soc. 2019;22:e25326. https://doi.org/10.1002/ jia2.25326

24. Bassett IV, Huang M, Cloete C, Candy S, Giddy J, Frank SC, et al. Assessing the completeness and accuracy of South African National Laboratory CD4 and viral load data: a cross-sectional study. BMJ Open. 2018;8:e021506. https:// doi.org/10.1136/bmjopen-2018-021506

25. McLaren ZM, Brouwer E, Ederer D, Fischer K, Branson N. Gender patterns of tuberculosis testing and disease in
South Africa. Int J Tuberc Lung Dis. 2015;19:104-10. https://doi.org/10.5588/ijtld.14.0212

26. Dlamini-Mvelase NR, Werner L, Phili R, Cele LP, Mlisana KP. Effects of introducing Xpert MTB/RIF test on multi-drug resistant tuberculosis diagnosis in KwaZuluNatal South Africa. BMC Infect Dis. 2014;14:442. https:/ / doi.org/10.1186/1471-2334-14-442

27. Nanoo A, Izu A, Ismail NA, Ihekweazu C, Abubakar I, Mametja D, et al. Nationwide and regional incidence of microbiologically confirmed pulmonary tuberculosis in South Africa, 2004-12: a time series analysis. Lancet Infect Dis. 2015;15:1066-76. https:/ / doi.org/10.1016/S14733099(15)00147-4

28. McIntosh AI, Jenkins HE, White LF, Barnard M, Thomson DR, Dolby T, et al. Using routinely collected laboratory data to identify high rifampicin-resistant tuberculosis burden communities in the Western Cape Province, South Africa: a retrospective spatiotemporal analysis. PLoS Med. 2018;15:e1002638. https:/ / doi.org/ 10.1371/journal.pmed.1002638

29. Cox H, Dickson-Hall L, Ndjeka N, Van't Hoog A, Grant A, Cobelens F, et al. Delays and loss to follow-up before treatment of drug-resistant tuberculosis following implementation of Xpert MTB/RIF in South Africa: a retrospective cohort study. PLoS Med. 2017;14:e1002238. https://doi.org/10.1371/journal.pmed.1002238

30. Naidoo P, Theron G, Rangaka MX, Chihota VN, Vaughan L, Brey ZO, et al. The South African tuberculosis care cascade: estimated losses and methodological challenges. J Infect Dis. 2017;216:S702-13. https:/ / doi.org/10.1093/ infdis/jix335

Address for correspondence: Sarah V. Leavitt, Boston University School of Public Health, Department of Biostatistics, Crosstown Bldg, 801 Massachusetts Ave, 3rd Fl, Boston, MA 02118, USA; email: sv1205@bu.edu 